\title{
Mitigating Construction Deficiencies: An Impact Analysis for Low-Cost Housing Developments Utilizing Artificial Neural Network
}

\author{
Ramene U. LIM ${ }^{\mathrm{a}, 1}$, Dante L. SILVA ${ }^{\mathrm{b}}$, and Kevin Lawrence M. DE JESUS ${ }^{\mathrm{a}}$ \\ ${ }^{a}$ School of Graduate Studies, Mapua University, Manila, Philippines \\ ${ }^{\mathrm{b}}$ School of Civil, Environmental, \& Geological Engineering, Mapua University, \\ Manila, Philippines
}

\begin{abstract}
The aim of this study is to be able to come up with a supplemental project management policy guidelines and computational tool that will address the two major concerns in construction of low-cost housing, construction delays and workmanship defects. Through assessment of previous studies, factors causing delays and defects from the two major stakeholders involved in housing development projects were identified. With the use of the five-point Likert Scale in survey forms distributed to 60 professionals involved in housing development projects, factors were classified and identified according to its degree of impact on the overall construction efficiency. The statistics of these factors were organized and used to develop an Artificial Neural Network Model. The relative importance of the factors was measured using Garson's Algorithm. The derived equations from the developed ANN Model were used in formulating the computational tool and supplemental policy guidelines that can now be used to evaluate the workmanship defects and delay ratings of different housing developments. The computational tool was tested by 10 experts with their current projects and was able to receive a 4.6 out of 5 rubric evaluation rating, showing the tool's effectiveness in identifying and assessing the probability and impact of construction deficiencies on their projects.
\end{abstract}

Keywords. Artificial Neural Network, Construction Delays, Construction Management Program, Mass Housing Developments, Workmanship Defects

\section{Introduction}

Construction is one of the most consistent and growing industries in the whole world. This industry is one of the greatest economic drivers of countries. Here in the Philippines, one of the government's main goals is the "Build, Build, Build!" Project [1]. However, these major programs with regards to construction only focuses on large scale structures [1]. There are only few programs that address the housing needs of the Filipino people $[2,3]$. There is an increase of $4 \%$ annually on the urbanization of major cities in the country $[4,5]$. With this, urban settlers who have the financial capacity prefer high-rise condominiums, while others settle with rooms for rent. Horizontal housing developments

\footnotetext{
${ }^{1}$ Corresponding Author: Ramene U. Lim, School of Graduate Studies, Mapua University, Manila, Philippines; E-mail: ramenelim@yahoo.com
} 
are left at the outskirts of the urban region and is handled with minimum supervision [6, $7]$, as it is an important aspect in construction management $[8,9]$. This results in major workmanship defects and construction delays caused by the involved stakeholders. In addition, the world is currently facing a pandemic in Covid-19 that requires people to stay indoors due to the high transmissibility of this virus. This increased further increased the need for housing units for workers with work from home arrangements and for students taking online classes. Due to the increase in demand for housing units coupled with the current challenge in experiencing delays and defects in ongoing housing projects, it is important that these construction deficiencies be mitigated to cope up with the housing demand.

The purpose of this study is to develop a supplementary construction policy guidelines and computational tool that will assist the users in mitigating these construction deficiencies. This study would identify the factors and assess its impact, identify the relative importance of each factor, and utilize ANN in developing the supplemental guidelines and computational tool.

\section{Literature Review}

There are different studies that identify the common causes of construction delays [10, $11,12]$ and workmanship defects of various construction projects [13]. These are the studies that were utilized to identify the most common construction deficiencies that lowcost housing developments experience. There is also an increasing trend in the usage of Artificial Neural Network in construction management $[11,14]$. There is usefulness to ANNs in carrying out a variety of prediction, classification, optimization, and modeling related tasks and it has significant benefits that make it a powerful tool for solving many problems in the field of construction management [15]. The utilization of ANN in the development of a computational tool will be helpful in validating the usage of ANNs specifically in housing projects.

\section{Methodology}

\subsection{Identification \& Classification of the Factors}

The sources of the factors are initially identified being the stakeholders involved in housing development projects. Different concepts of project management with relation to time and quality are reviewed and existing data from different related literatures that identifies the factors causing construction delays and workmanship defects are gathered to devise an assessment survey. The identified factors will comprise the assessment survey and will utilize a five-point Likert Scale. The survey was distributed to 60 professionals in the construction industry for impact assessment. Cronbach $\alpha$ assessment is used validate the internal consistency of the questionnaires. Statistics of the gathered data is evaluated in preparation to the formulation of the ANN Model. 


\subsection{Artificial Neural Network Model and Relative Importance of Factors}

The developed Artificial Neural Network model utilized a feed forward back propagation neural network model in predicting Construction Delays and Workmanship Defects rating. 4 ANN models were devised for this study in relation to the 4 data sets, Construction Delays Owner and Contractor Side, Workmanship Defects Owner and Contractor Side. Due to the similarity of the 4 data sets, identical criteria are were employed to the ANN Model.

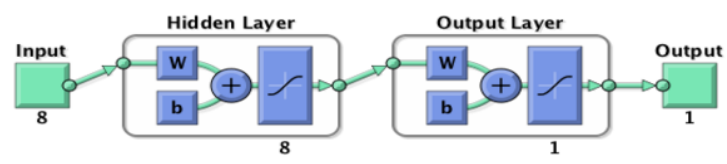

Figure 1. Design of the ANN Model

The training algorithm used for the model development of the 4 data sets was the Levenberg-Marquardt algorithm while the transfer function utilized is the hyperbolic tangent sigmoid function. The number of hidden neurons used for each model development is eight, equivalent to the number of input parameters such as the factors for each data set. The accuracy of the ANN models was evaluated based on the computed Pearson's Correlation Coefficient, Mean Squared Error and Mean Absolute Percentage Error. Utilizing the same ANN model, the study identified the relative importance of the factors using Garson's Algorithm.

\subsection{Supplemental Guidelines and Computational Tool}

Supplemental construction policy guidelines were devised based on the relative importance of each factor and the ANN model in preparation to the development of the computational tool. The computational tool was developed using the equations derived from the ANN model and will be distributed to professionals to validate its effectivity in evaluating construction delays and workmanship defects impact and probability ratings on existing and future housing developments.

\section{Results \& Discussion}

\subsection{Identification \& Classification of the Factors}

The sources of these factors are identified. These stakeholders are categorized as follows: Project Owner \& Contractor [7].

A study using artificial intelligence to predict risk delays in construction projects [12] identified 40 different factors that contribute to delays. Among the 40 factors, 8 are from the owner and 8 from contractors [12]. For this study, the researcher reclassified the delay sources according to the two major stakeholders involved in housing development projects. The Owner identified the following delay factors: A-Delay in payment processing, B-Owner decision making, C-Delay in preparing owner documents, D-the choice of inefficient contractor, E-the lack of a construction schedule, Factors F, $\mathrm{G}$, and $\mathrm{H}$ are possible political situations, poor information dissemination, and neighbor 
issues. Contractors: A-Problems with project planning and supervision, B-financial constraints C-poor internal communication, D-backlogs, E-poor labor, F-poor weather conditions, G-lack of construction materials, and H-unpredicted site conditions. This makes a total of 16 factors causing construction delays from owner and contractor side.

In a study on common workmanship defects in low-cost housing [16], 8 variables were identified as contributing to poor workmanship in project sites. The researcher used these sources to classify workmanship defects according to the two major stakeholders involved in housing development projects. The Owner identified the following workmanship defect factors: A-poor management supervision B-Refusal to pay for additional work, C-Approval of alternative materials, D-Shortening of work duration, EPoor owner/developer maintenance, F-Uncared turned over units, G-Unsupervised modification of units, and H-poor maintenance. Contractors: A-Complicated subcontractor roles, B-Laborer lack of skill, C-Unsuitable construction equipment, DPoor handling and storage of materials, E-Language/communication bar, F-Poor weather, G-vandalism, and H-nearby construction activities are all factors causing Workmanship Defects. This makes a total of 16 factors causing workmanship defects from owner and contractor side.

The 32 factors were assessed using a five-point Likert Scale. To assess the impact of each factor, 60 questionnaires were distributed to housing professionals with at least 5 years of experience. The Cronbach $\alpha$ rating for construction delays (owner side) questionnaire was 0.896 indicating a good internal consistency and the Cronbach $\alpha$ rating of the questionnaires for the construction delays (contractor side), work defects (owner and contractor side) were $0.935,0.918$, and 0.901 respectively, indicating an excellent internal consistency. The basic statistics for the 4 data sets are now established for the development of the ANN model.

\subsection{Artificial Neural Network Model}

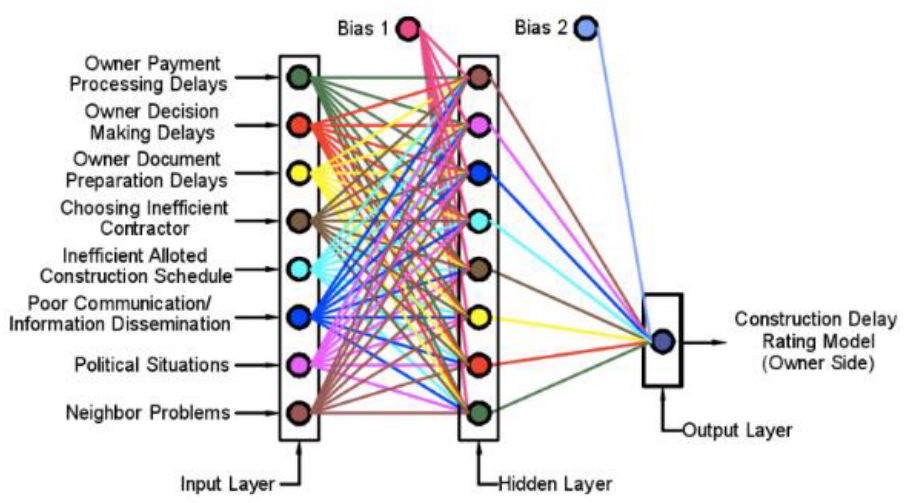

Figure 2. Architecture of Construction Delays Owner Side ANN Model

The developed Construction Delays rating model (Owner Side) has a $\mathrm{R}_{\text {all }}$ value of 0.99682 which is very high, and MSE and MAPE of 0.0040284 and $2.027 \%$, respectively, which are very low, indicating that the model has high correlation and less error.

The correlation between the actual and the predicted Construction Delays rating model (Owner Side) yielded a Pearson's Correlation Coefficient value of 0.99675 which 
suggests high correlation between the actual and the predicted Construction Delays rating model (Owner Side).

The derived prediction equation from the ANN model for the construction delay rating owner side using the weights and biases generated from the simulation will be utilized as the main driving components of the Computational Tool. Similarly, for the 3 remaining data sets Construction Delays Contractor Side, Workmanship Defects Owner $\&$ Contractor Side, same procedures were done to validate the reliability of the ANN model and derived equations.

\subsection{Relative Importance of Factors}

For the Construction Delay Owner side model, the ranking of importance of these factors is identified as Factor $\mathrm{H}<$ Factor $\mathrm{E}<$ Factor $\mathrm{D}<$ Factor $\mathrm{F}<$ Factor $\mathrm{G}<$ Factor $\mathrm{C}<$ Factor $\mathrm{A}<$ Factor $\mathrm{B}$ wherein Factor $\mathrm{H}-$ neighbor problems is the least influential factor with R.I. $=4.12895 \%$ and Factor $\mathrm{B}-$ owner decision making delays is the most influential factor with $\mathrm{RI}=18.13171 \%$.

For the Construction Delays Contractor Side model, the ranking of importance of these factors is identified as Factor $\mathrm{F}<$ Factor $\mathrm{E}<$ Factor $\mathrm{D}<$ Factor $\mathrm{H}<$ Factor $\mathrm{A}<$ Factor $\mathrm{B}<$ Factor $\mathrm{G}<$ Factor $\mathrm{C}$ wherein Factor $\mathrm{F}$ - poor weather conditions is the least influential factor with R.I. $=7.8220 \%$ and Factor $\mathrm{C}-$ poor internal communication is the most influential factor with RI $=17.2295 \%$.

For the Workmanship Defects Owner Side model, the ranking of importance of these factors is identified as Factor $\mathrm{F}<$ Factor $\mathrm{H}<$ Factor $\mathrm{D}<$ Factor $\mathrm{B}<$ Factor $\mathrm{E}<$ Factor $\mathrm{A}<$ Factor $\mathrm{G}<$ Factor $\mathrm{C}$ wherein Factor $\mathrm{F}$ - tenants/ users lack of care for their units is the least influential factor with R.I. $=7.3241 \%$ and Factor C - owner's refusal to pay for additional works is the most influential factor with $\mathrm{RI}=21.2203 \%$.

For the Workmanship Defects Contractor Side model, the ranking of importance of these factors is identified as Factor $\mathrm{E}<$ Factor $\mathrm{H}<$ Factor $\mathrm{F}<$ Factor $\mathrm{A}<$ Factor $\mathrm{G}<$ Factor $\mathrm{B}<$ Factor $\mathrm{C}<$ Factor D wherein Factor $\mathrm{E}$ - language/ communication barrier is the least influential factor with R.I. $=8.5079 \%$ and Factor $\mathrm{D}-$ poor handling and storage of materials is the most influential factor with $\mathrm{RI}=23.7942 \%$.

\subsection{Development of Supplemental Construction Policy Guidelines}

The supplemental guidelines can be accessed in the same web page as the computational tool. Each of the 32 factors were thoroughly defined for the user's reference. The guidelines will also define the required input from the user and the computational tool's output.

\subsection{Development of Computational Tool}

This study utilized Netlify, a web-based software development medium to develop the computational tool for this study. This web-based software utilizes Java code for the program of the tool. 


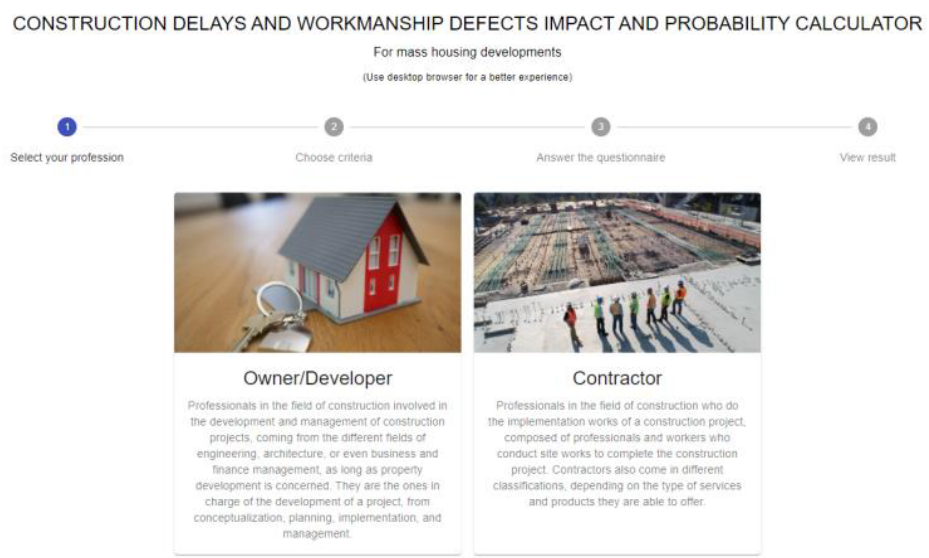

Figure 3. Computational Tool Home Page

The computational tool will request the user to input their affiliation and select the construction deficiency he/she would like to assess, construction delay or workmanship defects. Then the computational tool will display the eight (8) factors associated to the choice of the user. The user will be requested to rate each of the factors according to its probability of occurring on his/her housing project using a five-point Likert scale. The computational tool will produce an output that will show the impact and probability rating that the user's construction project will encounter.

Table 1. Computational Tool Impact \& Probability Rating

\begin{tabular}{lcl}
\hline Output Range & Impact Rating & Probability Rating \\
\hline Between 1 to 2 & 0-25\% Impact & Unlikely to happen \\
Between 2 to 3 & $25-50 \%$ Impact & Less likely to happen \\
Between 3 to 4 & $50-75 \%$ Impact & More likely to happen \\
Between 4 to 5 & $75-100 \%$ Impact & Most definitely will happen \\
\hline
\end{tabular}

Impact rating derived from the Neural Network Model identifies the degree of impact of the factor the construction project will encounter. For the construction delays, it is the percentage increase from the original schedule, while for the workmanship defects, it is the weighted percentage of work items that will encounter defects. Probability Rating is derived from the user's input on the computational tool, directly related to the factors' relative importance. This will identify the probability of occurrence of construction delays or workmanship defects of a construction project given the users input.

To validate the computational tool's usability and effectiveness, the researcher introduced the computational tool to 10 experts in housing development projects. These professionals have an average years of work experience at 20 years. The researcher utilized a rubric assessment given to the professionals after they have tried using the computational tool. The computational tool was able to achieve an average rating of 4.6 out of 5 for the whole assessment. The computational tool's clarity and visibility had the highest rating of 4.9 while the user's requirements and the uniqueness had the lowest rating at 4.4. This assessment was helpful in identifying the usability of the tool and its possible room for improvements. 


\section{Conclusion}

This study was able to utilize the implementation of artificial neural network in housing construction projects. The devised ANN model for the identified factors were able to derive the required equations for the computational tool. ANNs are modeled based on the input and output data and can be trained, having the potential in machine learning to always show updated results in utilizing new training examples. The developed supplemental construction policy guidelines and computational tool proved to be helpful in mitigating common construction deficiencies such as construction delays and workmanship defects having a 4.6 out of 5 rating in the rubric assessment given by the 10 professionals that tested the tool. The identified factors will give the users awareness regarding its impact on the project site, enabling them to address and prevent these deficiencies from occurring. However, this study is limited to the 32 identified factors that cause delays and work defects in low-cost housing projects, and the gathered data from the 60 respondents. The use of a web-based software for the development of the computational tool also allows it to be accessible to the users provided that they have access to a web browser and the internet. The computational tool also has the potential to be implemented in mobile-based app to further increase its accessibility.

\section{References}

[1] Build Build Build Philippine Infrastructure Transparency Program, build.gov.ph

[2] Revised Implementing Rules \& Regulations for BP220 - HLURB 2008

[3] Housing Article, Philippine Board of Investments, https://boi.gov.ph/ufaqs/housing/

[4] Mission and Vision - National Housing Authority, nha.gov.ph

[5] PSA Census of Population and Housing, https://psa.gov.ph

[6] L. Olofsson and S. Truong (2007), Sustainable Housing in Navotas, Philippines - A Minor Field Study on Low-income Housing in Disaster Prone Areas

[7] E. Adinyira, D. Ahadzie, and T. E. Kwofie (2013), Determining the Unique Features of Mass Housing Projects (MHPs)

[8] G. J. Ritz and S. M. Levy (2013), Total Construction Project Management, Second Edition

[9] B. Rajbhandari (2017), Construction Management in Mass Housing

[10] N. Braimah (2013), Construction Delay Analysis Techniques - A Review of Application Issues and Improvement Needs

[11] R. N. Macariola and D. L. Silva (2020), Coping with the Information Age: Development of a Data Flow Diagram-Based Knowledge Management System for Mitigating Delays for Construction

[12] Z. M. Yaseen, Z. H. Ali, S. Q. Salih, and N. Al-Ansari (2020), Prediction of Risk Delay in Construction Projects Using a Hybrid Artificial Intelligence Model

[13] H. Abdul Rahman, W. Chen, L. C. Wood, Y. M. Khoo (2014), Defects in Affordable Housing Projects in Klang Valley, Malaysia

[14] K. M. de Jesus, D. L. Silva, B. S. Villaverde, E. M. Adina (2020), Hybrid Artificial Neural Network and Genetic Algorithm Model for Multi-Objective Strength Optimization of Concrete with Surkhi and Buntal Fiber

[15] P. S. Kulkarni, S. N. Londhe, and M. C. Deo (2017), Artificial Neural Network for Construction Management: A Review

[16] N. A. Othman and M. A. Othuman Mydin (2014), Poor Workmanship in Construction of Low-Cost Housing 